\title{
Molybdenum Carbide Nano-Powder for Production of Mo-99 Radionuclides
}

\author{
Vladimir D. Risovany, Konstantin V. Rotmanov, Genady I. Maslakov, Yury D. Goncharenko, \\ Grigory A. Shimansky, Aleksandr I. Zvir, Irina M. Smirnova, Irina N. Kuchkina \\ Joint Stock Company, State Scientific Center-Research Institute of Atomic Reactors, Dimitrovgrad, Russia \\ Email: niiar@niiar.ru
}

Received November 25, 2011; revised December 14, 2011; accepted January 30, 2012

\begin{abstract}
At present, there are two ways to produce ${ }^{99} \mathrm{Mo}$ in a reactor: 1) fission process-from $\mathrm{U}$ fission product by reaction ${ }^{235} \mathrm{U}$ $(\mathrm{n}, \mathrm{f}){ }^{99} \mathrm{Mo}$ and 2) activation process - by radiation capture reaction ${ }^{98} \mathrm{Mo}(\mathrm{n}, \gamma){ }^{99} \mathrm{Mo}$. This paper presents the results of experiments performed with molybdenum carbide nano-powder to produce ${ }^{99}$ Mo. These results show the implementation of the above idea in practice.
\end{abstract}

Keywords: Carbide Nano-Powder; Molybdenum-99; Activation Process; Fission Process

\section{Introduction}

At present, there are two ways to produce ${ }^{99} \mathrm{Mo}$ in a reactor: 1) fission process - from $U$ fission product by reaction ${ }^{235} \mathrm{U}$ (n, f) ${ }^{99}$ Mo and 2) activation process - by radiation capture reaction ${ }^{98} \mathrm{Mo}(\mathrm{n}, \gamma){ }^{99} \mathrm{Mo}$.

The main advantage of ${ }^{99} \mathrm{Mo}$ production from U fission products is a possibility to have large amounts of the final radionuclide ${ }^{99} \mathrm{Mo}$ of a high specific activity (more than ten thousand $\mathrm{Ci} / \mathrm{g}$ ) per one production cycle with practically no carrier. In U fission, the total ${ }^{99}$ Mo yield makes up $6 \%$ in average. At a neutron flux density of about $10^{14} \mathrm{n} /\left(\mathrm{cm}^{2} \mathrm{~s}\right)$, the maximum ${ }^{99}$ Mo accumulation is achieved in $5-7$ days from the beginning of the target irradiation. There is only one significant drawback in this way of ${ }^{99}$ Mo production that is a large amount of radwaste that contains more than $97 \%$ of the initial $U$ in the target. The remaining ${ }^{235} \mathrm{U}$ isotopes can be extracted from radwaste for further treatment but this is rather a costly process.

The activation process of ${ }^{99}$ Mo production by reaction ${ }^{98} \mathrm{Mo}(\mathrm{n}, \gamma){ }^{99} \mathrm{Mo}$ has a great advantage that is practically no radwaste. In addition, when producing molybdenum by the above process, there is no problem with the purification of the final ${ }^{99} \mathrm{Mo}$ from high-active ${ }^{235} \mathrm{U}$ fission product impurities as compared to the fission one. The cost of a ${ }^{99}$ Mo activity unit produced by the activation process is an order of magnitude lower as compared to the ${ }^{235} \mathrm{U}$ fission product reprocessing. The main disadvantage of this process is the low specific activity of the final ${ }^{99} \mathrm{Mo}$ radionuclide that is several $\mathrm{Ci} / \mathrm{g}$. It makes the activation process unsuitable for a commercial produc- tion of sorption-type ${ }^{99 \mathrm{~m}} \mathrm{Tc}$ generators.

When producing ${ }^{99}$ Mo by the activation process, molybdenum oxide $\left(\mathrm{MoO}_{3}\right)$ is used as a target, as a rule [1]. The irradiated target is reprocessed by dissolving molybdenum oxide in alkali with further correction of the solution composition depending on the way of the generator production [2]. The solution, along with the final ${ }^{99} \mathrm{Mo}$, contains a significant amount of a carrier (nonactivated ${ }^{99} \mathrm{Mo}$ and other Mo isotopes if a target was made from natural Mo). In this case, the specific activity of produced ${ }^{99} \mathrm{Mo}$ is about 1-5 Ci/g [3]. The purpose of this paper is to search for a way of selective extraction of final ${ }^{99}$ Mo from the irradiated target.

Molybdenum carbide nano-power was proposed as a target since it has a well-developed surface that can achieve from tens to hundreds square meters per on gram of powder. The particle surface can be considered as a grain boundary that is an extended defect able to accumulate inter-crystalline segregations. Under irradiation, atoms capture neutrons and turn into excited state. Further, during the decay, energy releases that is enough to destroy the chemical bonding of atoms in a molecule. Atoms go out of the crystalline lattice and may come to the grain boundaries. The surface is like a trap for any non-uniform elements of the material base structure. Atoms of non-uniform elements achieved the surface have an advantage from the energy viewpoint since they can concentrate on grain surfaces. In this case, they can be easily dissolved chemically in alkali or acid solutions.

For the first time the idea of using nano-powders for radio nuclides accumulation was published in 2006 and patented [4]. This paper presents the results of experi- 
ments performed with molybdenum carbide nano-powder to produce ${ }^{99} \mathrm{Mo}$. These results show the implementation of the above idea in practice.

\section{Investigation of Molybdenum Carbide Powder Structure}

Molybdenum carbide with the natural Mo isotopes content was used, Table 1. Molybdenum carbide powder was examined at the super-high resolution field-emission scanning electron microscope Zeiss SUPRA55VP equipped with energy dispersive spectrometer Inca Energy 350, wave dispersive spectrometer Inca Wave 500 and HKL Electron Back Scatter Diffraction Premium registration and analysis system.

We applied some amount of powder $(2-5 \mathrm{mg})$ on an Agar electro-conductive band and put it into the microscope vacuum chamber.

Figure 1 presents high magnification secondary electron image of nano-powder particles at accelerating voltage $20 \mathrm{kV}$.

Then, we examined separate areas by energy dispersive spectrometer Inca Energy 350, registered X-ray characteristic spectra and analyzed the chemical element composition of these areas.

Powder particles were of a globular shape and their sizes varied from 10 to $50 \mathrm{~nm}$. However, the majority of particles was about $20-40 \mathrm{~nm}$ in size.

It should be mentioned that the examination of the chemical element composition of separate nano-powder particles by SEM is impossible since the typical dimension of the X-ray excitation area (about $1 \mu \mathrm{m}$ ) comprising data on the material elementary composition were certainly larger than the physical size of a particle. This area may consist of not only numerous powder particles but also of carbon-containing substrate that makes difficult the evaluation of the real carbon content in the powder. Besides, the evaluation of the carbon content may be affected by the thickness of a carbon-containing film (the same refers to oxygen) that appears on any surface being in contact with air for some time.

Table 2 presents the results of the chemical composition examination. The ultimate composition of the nanopowder consists, mainly, of molybdenum and carbon. There can be insignificant impurities of calcium and platinum.

\section{Irradiation in Research Reactor RBT-6}

There were fabricated four quartz capsules with molybdenum carbide powder, Figure 2 and Table 3 present the powder mass per each capsule. The capsules were placed into an irradiation rig (Figure 3) that was loaded into an FA cell. Irradiation was performed in RBT-6 channel 4 for 10 effective days until the calculated amount of ${ }^{99} \mathrm{Mo}$
Table 1. Mo isotopes.

\begin{tabular}{cc}
\hline Nuclide & Content, $\%$ \\
\hline${ }^{92} \mathrm{Mo}$ & 15.5 \\
${ }^{94} \mathrm{Mo}$ & 9.4 \\
${ }^{95} \mathrm{Mo}$ & 16.1 \\
${ }^{96} \mathrm{Mo}$ & 16.7 \\
${ }^{97} \mathrm{Mo}$ & 9.4 \\
${ }^{98} \mathrm{Mo}$ & 23.6 \\
${ }^{100} \mathrm{Mo}$ & 9.2 \\
\hline
\end{tabular}

Table 2. Chemical composition of the nano-powder.

\begin{tabular}{cccccc}
\hline Spectrum & $\mathrm{C}$ & $\mathrm{O}$ & $\mathrm{Ca}$ & $\mathrm{Mo}$ & $\mathrm{Pt}$ \\
\hline Spectrum 1 & 57.72 & 10.85 & 0.26 & 30.40 & 0.77 \\
Spectrum 2 & 60.48 & 10.03 & 0.21 & 28.49 & 0.79 \\
Spectrum 3 & 60.98 & 10.34 & 0.25 & 27.68 & 0.75 \\
Spectrum 4 & 60.02 & 9.38 & & 29.75 & 0.84 \\
Spectrum 5 & 65.01 & 7.03 & 0.21 & 27.76 & \\
Spectrum 6 & 64.12 & 8.97 & 0.34 & 26.56 & \\
\hline
\end{tabular}

Table 3. Amount of molybdenum carbide powder in capsules.

\begin{tabular}{ccc}
\hline Capsule No & $\begin{array}{c}\text { Weighted amount, } \\
\mathrm{mg}\end{array}$ & $\begin{array}{c}\text { Mo content in } \\
\text { weighted amount, mg }\end{array}$ \\
\hline $\mathbf{1}$ & 354.75 & 71.66 \\
$\mathbf{2}$ & 354.05 & 71.52 \\
$\mathbf{3}$ & 354.45 & 71.60 \\
$\mathbf{4}$ & 395.05 & 79.80 \\
\hline
\end{tabular}

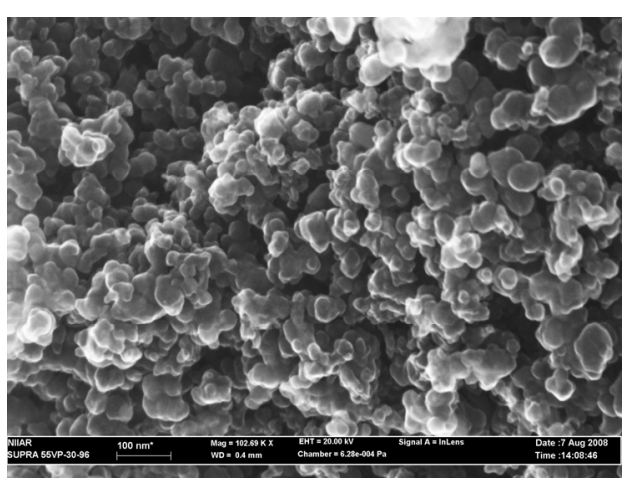

Figure 1. $\mathrm{Mo}_{2} \mathrm{C}$ nano-powder particles.

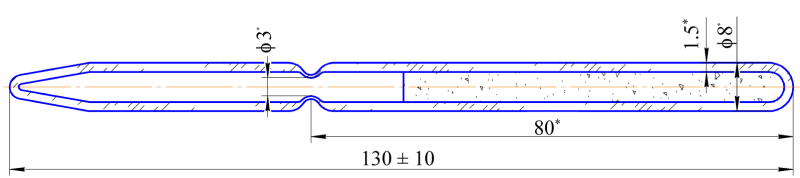

Figure 2. Capsule (target) design with $\mathrm{Mo}_{2} \mathrm{C}$ powder. 


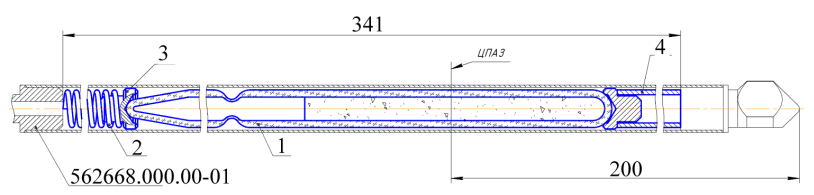

Figure 3. Irradiation rig design.

with a specific activity of about $1 \mathrm{Ci} / \mathrm{kg}$ was accumulated.

The Mo activation was calculated at a neutron flux density of $1.16 \times 10^{14} \mathrm{~cm}^{-2} \times \mathrm{s}^{-1}(\mathrm{E}>0), 5.17 \times 10^{13} \mathrm{~cm}^{-2}$ $\times \mathrm{s}^{-1}(\mathrm{E}>0.1 \mathrm{MeV})$ and reactor power $6 \mathrm{MW}$. To calculate the rate of inelastic interaction reactions between neutrons and nuclei, the ADL- 3 cross-section library was used. The radionuclide constants were taken from the FENDL-2 data file. The kinetics of nuclide concentrations under irradiation was calculated by the TRANS_MU code. All the calculation results are in $\mathrm{Bq} / \mathrm{g}$ unit that is the activity of radionuclide in $1 \mathrm{~g}$ of molybdenum at the end of irradiation.

Figures $\mathbf{4}$ and $\mathbf{5}$ present the ${ }^{99}$ Mo decay scheme and its specific activity vs. irradiation time.

It can be seen that the ${ }^{99}$ Mo specific activity becomes practically stationary after irradiation for 15 effective days ( $97.4 \%$ from the stationary value). After irradiation for 10 effective days, this value is $91.7 \%$ from the stationary one and it is $71.5 \%$ after irradiation for 5 effective days. Since the specific activity of a long-lived ${ }^{93}$ Mo nuclide increases almost linearly, then, from the viewpoint of a purity of ${ }^{99}$ Mo generating nuclide in irradiated molybdenum, the minimal irradiation period is more preferable. All radio nuclides involved into the calculations have half-lives less than 1 minute and activity no less than $1000 \mathrm{~Bq} / \mathrm{g}$. Their activities are given in Table 4. The relative decrease of ${ }^{99} \mathrm{Mo}$ activity observed during its cooling for 60 days is shown in Figure 6.

\section{Extraction of ${ }^{99}$ Mo from Irradiated Material}

${ }^{99}$ Mo was extracted as soon as capsules were removed from the reactor. The capsules preserved their integrity. Powder $\mathrm{Mo}_{2} \mathrm{C}$ did not differ from its initial state. It freely ran inside capsules when we overturned them. Close to the capsules, the gamma-emission dose rate did not exceed $1000 \mu \mathrm{Sv} / \mathrm{h}$. Gamma-spectra from the capsules were measured and they showed the dominant presence of ${ }^{99}$ Mo, Figure 7.

The capsules were placed into a glove box and opened. SEM sowed that the size of molybdenum carbide particles remained the same, Figure 8.

We added $2 \mathrm{~cm}^{3}$ of $1 \times 10^{-4} \mathrm{~mol} / 1 \mathrm{KOH}$ into a test tube with molybdenum carbide and agitated the mixture for 5 minutes. Then, the suspension was filtrated through a double "blue ribbon" filter into a $25 \mathrm{~cm}^{3}$ volumetric tube. The deposit remained on the filter was washed $5-6$
Table 4. Activities of radio nuclides in irradiated molybdenum, Bq/g.

\begin{tabular}{ccccc}
\hline \multirow{2}{*}{ Radionuclide } & $\mathbf{T}_{\mathbf{1} / \mathbf{2}}$ & \multicolumn{4}{c}{ Irradiation time, days } \\
\cline { 3 - 5 } & & $\mathbf{5}$ & $\mathbf{1 0}$ & $\mathbf{1 5}$ \\
\hline${ }^{89} \mathrm{Zr}$ & 3.27 days & $1.20 \times 10^{6}$ & $1.61 \times 10^{6}$ & $1.76 \times 10^{6}$ \\
${ }^{89 \mathrm{~m}} \mathrm{Zr}$ & $4.18 \mathrm{~min}$ & $5.74 \times 10^{5}$ & $5.74 \times 10^{5}$ & $5.74 \times 10^{5}$ \\
${ }^{91 \mathrm{~m}} \mathrm{Nb}$ & 62 days & 72784 & $1.42 \times 10^{5}$ & $2.07 \times 10^{5}$ \\
${ }^{92 \mathrm{~m}} \mathrm{Nb}$ & 10.1 days & $6.86 \times 10^{7}$ & $1.17 \times 10^{8}$ & $1.52 \times 10^{8}$ \\
${ }^{93} \mathrm{Mo}$ & $3 \times 10^{3}$ years & 16,500 & 33,000 & 49,500 \\
${ }^{99} \mathrm{Mo}$ & 2.75 days & $2.64 \times 10^{10}$ & $3.39 \times 10^{10}$ & $3.61 \times 10^{10}$ \\
${ }^{101} \mathrm{Mo}$ & $14.6 \mathrm{~min}$ & $1.08 \times 10^{10}$ & $1.08 \times 10^{10}$ & $1.08 \times 10^{10}$ \\
${ }^{102} \mathrm{Mo}$ & $11.2 \mathrm{~min}$ & 3560 & 3560 & 3560 \\
${ }^{99} \mathrm{Tc}$ & $2.11 \times 10^{5}$ years & 642 & 2010 & 3580 \\
${ }^{99 \mathrm{~m}} \mathrm{Tc}$ & $6.01 \mathrm{~h}$ & $2.24 \times 10^{10}$ & $2.96 \times 10^{10}$ & $3.17 \times 10^{10}$ \\
${ }^{101} \mathrm{Tc}$ & $14.2 \mathrm{~min}$ & $1.08 \times 10^{10}$ & $1.08 \times 10^{10}$ & $1.08 \times 10^{10}$ \\
\hline
\end{tabular}

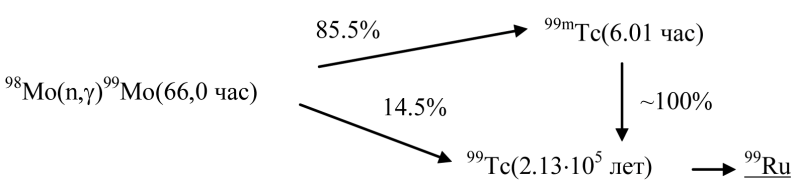

Figure 4. ${ }^{99}$ Mo decay scheme.

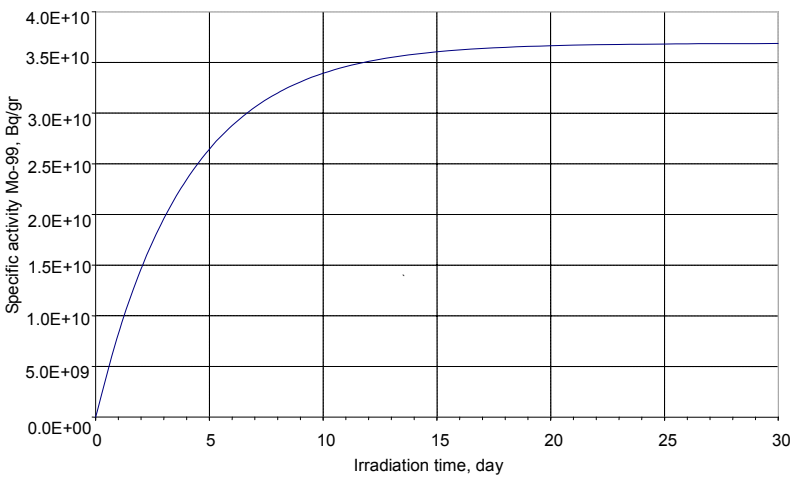

Figure 5. ${ }^{99}$ Mo specific activity vs. irradiation time.

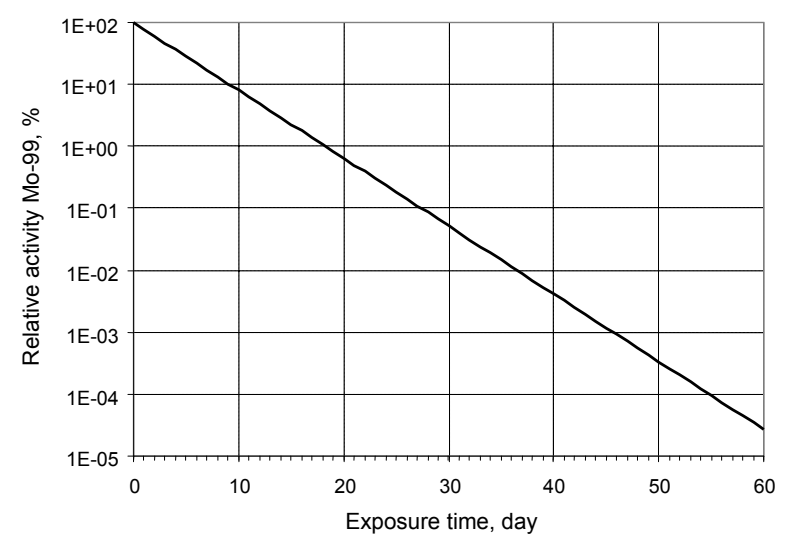

Figure 6. Decrease of ${ }^{99} \mathrm{Mo}$ relative activity after irradiation. 


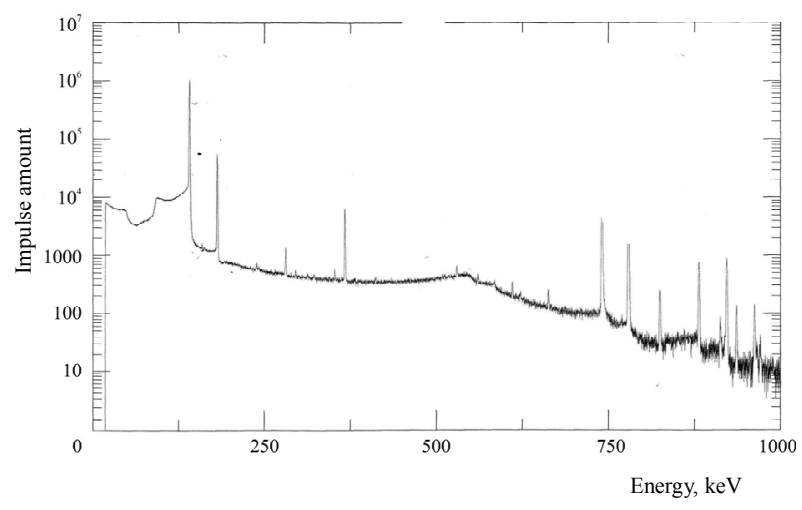

Figure 7. Gamma-spectrum of an irradiated Mo sample.

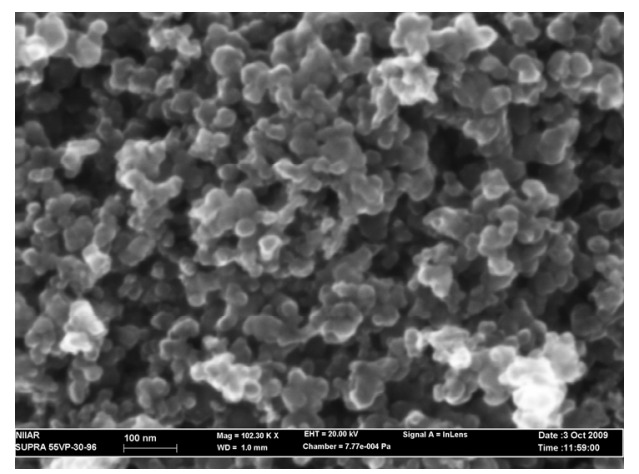

Figure 8. $\mathrm{Mo}_{2} \mathrm{C}$ nano-powder particles after irradiation in RBT-6.

times with de-ionized water, the filtrate color being darkgreen. Then, there was one more filtration though the "blue ribbon" filter. The final filtrate volume made up $20.5 \mathrm{~cm}^{3}$. Then, $1 \mathrm{~cm}^{3}$ of filtrate was diluted with deionized water by 10000 times and $50 \mathrm{~cm}^{3}$ of solution was placed into a screw-top plastic glass $(\varnothing 40 \mathrm{~mm}, \mathrm{H}=60$ $\mathrm{mm})$ and sent for radiometry. It took $\sim 1.5$ hours to extract ${ }^{99}$ Mo. Table 5 presents the measured filtrate samples activities.

Quartz capsule No.4 was opened the next day, on 09. 09.2009. Molybdenum carbide powder was poured into a $5 \mathrm{~cm}^{3}$ test tube through a fennel (visually, almost all powder was removed from the capsule). The gamma emission rate from the powder made up $\sim 350 \mu \mathrm{Sv} / \mathrm{h}$. We added $2 \mathrm{~cm}^{3}$ of $0.1 \mathrm{~mol} / 1 \mathrm{KOH}$ into a test tube with molybdenum carbide and agitated the mixture for 5 minutes. Then, the suspension was filtrated through a double "blue ribbon" filter into a $25 \mathrm{~cm}^{3}$ volumetric tube. The deposit remained on the filter was washed 5 - 6 times with deionized water, the filtrate color being yellow. Then, there was one more filtration though the "blue ribbon" filter. The final filtrate volume made up $14.5 \mathrm{~cm}^{3}$.

We sampled $1 \mathrm{~cm}^{3}$ to measure the ${ }^{99} \mathrm{Mo}$ and ${ }^{99 \mathrm{~m}} \mathrm{Tc}$ activity. Then, $1 \mathrm{~cm}^{3}$ of filtrate was diluted with deionized water by 10,000 times and $50 \mathrm{~cm}^{3}$ of solution was placed into a screw-top plastic glass $(\varnothing 40 \mathrm{~mm}, \mathrm{H}=60 \mathrm{~mm})$ and
Table 5. Measured activities of filter solutions and filtrates samples.

\begin{tabular}{|c|c|c|c|c|}
\hline $\begin{array}{c}\text { Capsule } \\
\text { No. }\end{array}$ & Operation & $\begin{array}{c}\text { Filtrate } \\
\text { activity, Bq }\end{array}$ & $\begin{array}{c}\text { Weighted } \\
\text { amount } \\
\text { activity, Bq }\end{array}$ & $\begin{array}{c}{ }^{99} \mathrm{Mo} \\
\text { specific } \\
\text { activity } \\
\text { Ci/g Mo }\end{array}$ \\
\hline 3 & $\begin{array}{c}\text { Powder washing } \\
0.0001 \mathrm{~mol} / 1 \mathrm{KOH}\end{array}$ & $3.3 \times 10^{8}$ & - & - \\
\hline \multirow{2}{*}{4} & $\begin{array}{c}\text { Powder washing } \\
0.1 \mathrm{~mol} / 1 \mathrm{KOH}\end{array}$ & $7.0 \times 10^{8}$ & \multirow{2}{*}{$3.5 \times 10^{9}$} & \multirow{2}{*}{1.2} \\
\hline & $\begin{array}{l}\text { Dissolution of filter } \\
\text { in } \mathrm{H}_{2} \mathrm{SO}_{4}+\mathrm{H}_{2} \mathrm{O}_{2}\end{array}$ & $2.8 \times 10^{9}$ & & \\
\hline \multirow{2}{*}{2} & $\begin{array}{c}\text { Powder washing } \\
0.1 \mathrm{~mol} / 1 \mathrm{KOH}\end{array}$ & $8.9 \times 10^{8}$ & \multirow{2}{*}{$2.3 \times 10^{9}$} & \multirow{2}{*}{0.9} \\
\hline & $\begin{array}{l}\text { Dissolution of filter } \\
\text { in } \mathrm{H}_{2} \mathrm{SO}_{4}+\mathrm{H}_{2} \mathrm{O}_{2}\end{array}$ & $1.4 \times 10^{9}$ & & \\
\hline \multirow{2}{*}{1} & $\begin{array}{c}\text { Powder washing } \\
0.0001 \mathrm{~mol} / 1 \mathrm{KOH}\end{array}$ & $5.6 \times 10^{8}$ & \multirow{2}{*}{$1.8 \times 10^{9}$} & \multirow{2}{*}{0.7} \\
\hline & $\begin{array}{l}\text { Dissolution of filter } \\
\text { in } \mathrm{H}_{2} \mathrm{SO}_{4}+\mathrm{H}_{2} \mathrm{O}_{2}\end{array}$ & $1.2 \times 10^{9}$ & & \\
\hline
\end{tabular}

sent for radiometry. All operations took $\sim 2$ hours. The results of the filtrate sample activity measurement are given in Table 5.

The activity of filtrates and filter solutions was measured at gamma-spectrometer with an HPGe-detector and DSPEC $^{\text {PLUS }}$ analyzer (EG\&G ORTEC). All the filtrates and filter solutions were measured in the same plastic glasses with covers $\varnothing 40 \times 55 \mathrm{~mm}$; the volume of each solution to be measured was $50 \mathrm{ml}$.

To have a high recording accuracy, the spectrometer was calibrated by means of a certified standard source ${ }^{152} \mathrm{Eu}\left(\rho=1.01 \Gamma / \mathrm{cm}^{3}\right)$ for volume of $50 \mathrm{ml}$.

${ }^{99}$ Mo characteristics are given in Table 6.

The filtrates were cooled for about 1.5 months. During this time, practically all Mo-99 decayed that allowed us to subject these solutions to chemical analysis to evaluate the content of the carrier-stable molybdenum. The analysis was done at the "Spectroflame Module S" ICP fieldemission spectrometer and the results are given in Table 7. The data on the content of stable molybdenum allowed us to calculate the specific activity of Mo-99 (in filtrates) as well as to evaluate the level of filtrates "en- richment" in Mo-99, i.e. to see how much the filtrate activity was higher than the specific of the whole weighted amount. As it can be seen from Table 6, the "enrichment" of filtrates No. 1 and No. 2 made up 1.5 and 1.6, respectively. The "enrichment" of filtrate No. 4 was different that could be explained by the insufficient amount of the washing solution $(14.5 \mathrm{ml})$ as compared to filtrates No. 1 and No. 2 (20 and $25 \mathrm{ml}$, respectively). So, some amount of Mo-99 could remain in the filtrate.

\section{Discussion}

Figure 9 presents the crystalline structure of molybdenum carbide. Atoms of molybdenum and carbon are lo- 
Table 6. ${ }^{99}$ Mo characteristics.

\begin{tabular}{cccc}
\hline Reaction & $\mathrm{T}_{1 / 2}$, day & $\mathrm{E}_{\gamma}, \mathrm{keV}$ & yield $\mathrm{E}_{\gamma} \%$ \\
\hline & & $140.5\left(+{ }^{99 \mathrm{~m}} \mathrm{Tc}\right)$ & $4.52(+88.8)$ \\
& & 181.1 & 6.08 \\
${ }^{98} \mathrm{Mo}(\mathrm{n}, \gamma){ }^{99} \mathrm{Mo}$ & 366.5 & 1.16 \\
& 2.75 & 739.4 & 12.1 \\
& & 778.8 & 4.36 \\
\hline
\end{tabular}

Table 7. Characteristics of $\mathrm{Mo}_{2} \mathrm{C}$ powder treatment for capsules No. 1, $2,4$.

\begin{tabular}{ccccccccc}
\hline Capsule No. & $\begin{array}{c}\text { Concentration } \\
\text { KOH } \\
\text { mol/1 }\end{array}$ & $\begin{array}{c}\text { Mo content in } \\
\text { weighted } \\
\text { amount, mg }\end{array}$ & $\begin{array}{c}\text { Mo content in } \\
\text { filtrate, mg }\end{array}$ & $\begin{array}{c}\text { Activity of } \\
\text { weighted } \\
\text { amount, Bq }\end{array}$ & $\begin{array}{c}\text { Activity of } \\
\text { filter, Bq }\end{array}$ & $\begin{array}{c}\text { Specific activity of } \\
\text { weighted amount, } \\
\text { Ci/g Mo }\end{array}$ & $\begin{array}{c}\text { Specific activity } \\
\text { of filtrate, } \\
\text { Ci/g Mo }\end{array}$ & $\begin{array}{c}\text { Enrichment } \\
\text { (n) }\end{array}$ \\
\hline 1 & $1 \times 10^{-4}$ & 71.66 & 13.39 & $1.8 \times 10^{9}$ & $5.6 \times 10^{8}$ & 0.7 & 1.13 & 1.6 \\
2 & 0.1 & 71.52 & 17.84 & $2.3 \times 10^{9}$ & $8.9 \times 10^{8}$ & 0.9 & 1.35 & 1.5 \\
4 & 0.1 & 79.80 & 14.998 & $3.5 \times 10^{9}$ & $7.0 \times 10^{8}$ & 1.2 & 1.28 & 1.07 \\
\hline
\end{tabular}

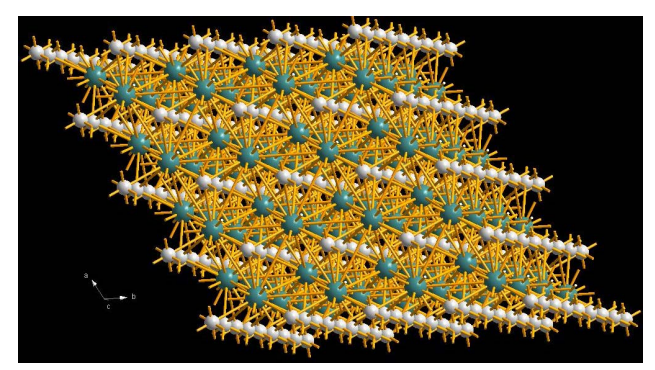

Figure 9. $\mathrm{Mo}_{2} \mathrm{C}$ crystalline structure.
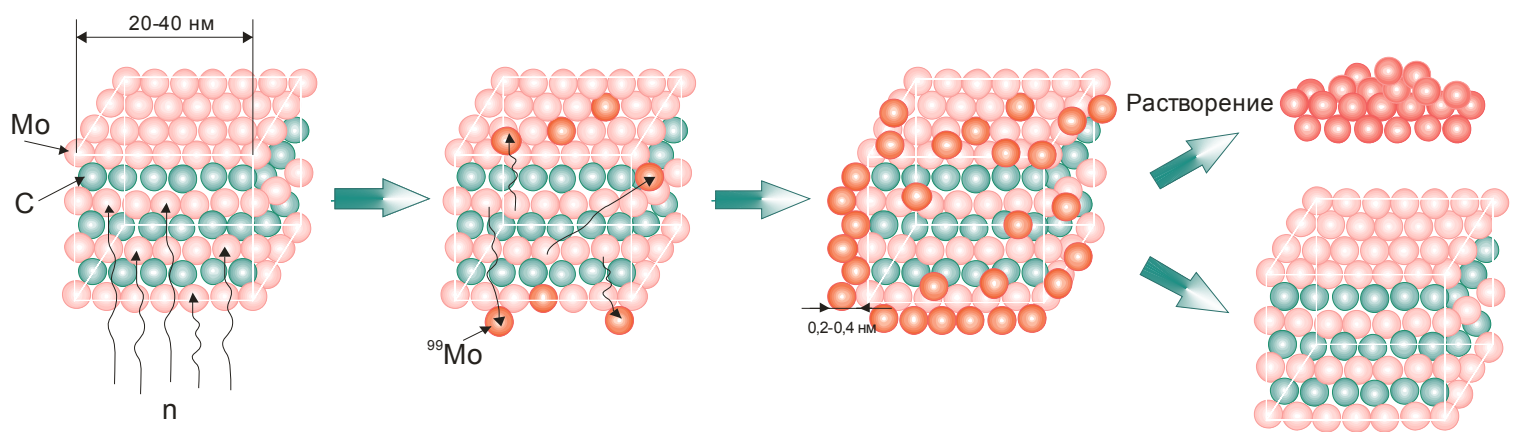

Figure 10. Production of ${ }^{99}$ Mo from molybdenum carbide nano-powder.

cated in layers and come out to the particles surfaces. Under irradiation, the following mechanisms could be considered. As a neutron is captured, a molybdenum nucleus becomes excited and, as a gamma-quantum is emitted, energy starts releasing that exceeds significantly the chemical bound energy of atoms in the lattice. It allows the generated radionuclide to move out of the lattice at a rather long distance. The surface of powder particles is a good barrier (trap), on which radio nuclides escaped from the lattice accumulate. The second mechanism is when near-surface molybdenum atoms capture neutrons. For these atoms, due to self-shielding, the capture rates could be higher as compared to those located at a dis- tance from the surface.

The examined molybdenum carbide nano-powder has a very developed surface that achieves tens and hundreds of square meters per one gram of powder. In this case, after irradiation, ${ }^{99}$ Mo accumulated on the surface can be converted into solution by dissolving a thin near-surface layer about several atom layers thick. The above mechanism is schematically shown in Figure 10.

The performed examinations showed that this scheme can be principally used for the ${ }^{99}$ Mo production. It has several advantages that are, first of all, minimization of waste, simple production operations and low cost. The whole process from the completion of irradiation to the 
production of solution with ${ }^{99}$ Mo takes several hours.

It is quite evident that the ${ }^{99} \mathrm{Mo}$ specific activity of more than $50 \mathrm{Ci} / \mathrm{g}$ can be achieved if we produce $\mathrm{Mo}_{2} \mathrm{C}$ nano-powder with Mo enrichment from $24.1 \%$ to $99 \%$ in ${ }^{99} \mathrm{Mo}$ and irradiate it in higher neutron flux (5 - 10 times higher), in the SM reactor, for instance. Such specific activity can be achieved only under irradiation in a high-flux research reactor. It is expected that if the size of molybdenum carbide nano-powder particles and chemical agent is optimized, the extraction of ${ }^{99} \mathrm{Mo}$ from a target by simple washing may achieve more than $40 \%$, the target being preserved and reused.

It is expedient to use molybdenum enriched in ${ }^{98} \mathrm{Mo}$ since more pure solution with ${ }^{99} \mathrm{Mo}$, i.e. less contaminated with other radio nuclides, can be produced. It is known that the following impurities may generate under irradiation of natural molybdenum: ${ }^{93} \mathrm{Mo}\left(\mathrm{T}_{1 / 2}=3.5 \times\right.$ $10^{3}$ years) from ${ }^{92}$ Mo converting into ${ }^{93 \mathrm{~m}} \mathrm{Nb}\left(\mathrm{T}_{1 / 2}=13.6\right.$ years) and then into ${ }^{93} \mathrm{Nb} ;{ }^{101} \mathrm{Mo}\left(\mathrm{T}_{1 / 2}=14.6 \mathrm{~min}\right)$ from ${ }^{100}$ Mo generating ${ }^{101} \mathrm{Tc}\left(\mathrm{T}_{1 / 2}=14.2 \mathrm{~min}\right)$ when decaying and then ${ }^{101} \mathrm{Ru}$ [3]. Besides, ${ }^{188} \mathrm{~W}\left(\mathrm{~T}_{1 / 2}=75\right.$ days) and daughter ${ }^{188} \operatorname{Re}\left(\mathrm{T}_{1 / 2}=167 \mathrm{~h}\right)$ generating ${ }^{188} \mathrm{Os}$ when decaying may be observed in irradiated samples in the form of impurity radio nuclides because of insufficient purification of molybdenum from foreign-metal impurities.

\section{REFERENCES}

[1] E. L. R. Hetherington and R. E. Boyd, "Targets for the Production of Neutron Activated Molybdenium-99," Proceedings of the IAEA Consultants Meeting, Faure Island, 10-12 April 1997, pp. 19-24.

[2] G. E. Kodina and V. N. Korsunsky, "Status and Progress of Application of Tc-99m Radiopharmaceuticals in Russia," Radiochemistry, Vol. 39, No. 5, 1997, pp. 385-388.

[3] M. P. Zykovand and G. E. Kodina, "Methods for ${ }^{99} \mathrm{Mo}$ Production," Radiochemistry, Vol. 41, No. 3, 1999, pp. 193-204.

[4] G. I. Maslakov, V. G. Maslakov and L. G. Babikov, "Production of ${ }^{99 \mathrm{~m}} \mathrm{Tc}$ and ${ }^{188} \mathrm{Re}, " \mathrm{RF}$ Patent No. 2268516 , 2006. 